\section{Grains of Sand and an Artist's Hands}

To the Editor,

About the Author: Angela Peterman Mihalic, M.D. is Associate Dean for Studen Affairs and Professor of $\mathrm{Pe}$ diatrics at the University of Texas Southwestern Medical school.

Submission: Mar 9, 2015 Acceptance: Mar 9, 2015 Publication: Mar 15, 2015
It is with great pride that I write this Letter to the Editor on behalf of Ms. Shelly Mingqian Xie, our second-year medical student at the University of Texas Southwestern Medical School, whose work has been featured this year by your journal.

Shelly is a unique individual who has an extraordinary gift for the arts in all forms, along with a deep understanding of the human condition and how disease impacts individuals, families, and society at large. She has the ability to combine her artistic gifts with her love of science to make a powerful and significant impact on health.

Coming to the U.S. at the age of 12 , it did not take long for Shelly to excel academically and discover her gifts for drawing and painting. While serving as a hospital volunteer during high school, she began a program painting portraits of patients during emotionally difficult times, such as a mother holding a stillborn baby or a dying young man. Through these experiences and the conversations she had with patients as she drew their portraits, Shelly developed a greater understanding of the impact of disease, illness, loss and death; the importance of communication, empathy and compassion; and the resilience of the human spirit despite devastating circumstances. This first important step of combining her art with science planted the seed that led to her pursuit of medicine as a future physician.

After researching Schistosomiasis during her undergraduate years at Stanford, she had another opportunity to combine art, the humanities, and science. Her new understanding of the devastating global impact of this preventable and treatable disease inspired her to self-learn a new 3D art media - sand art - to tell the story of families impacted by Schistosomiasis, and later Chagas and hookworm disease.

It did not take long for national and international organizations to appreciate the powerful impact this art form, combined with storytelling through live or recorded demonstrations, could have on neglected tropical diseases. Even during her medical school coursework here at UT Southwestern Medical Center, Shelly has presented her work at national and international conferences to promote education, public health interventions, and treatment to improve the health of families impacted by these diseases. Very few medical students have had such a worldwide impact on health and health promotion at such an early stage in their careers.

After having the great pleasure of getting to know her well as a person, it is clear that there are few students as humble, truly empathetic, and sincere as Shelly Xie. Her life experiences, appreciation for diverse cultures, experiences getting to know hundreds of patients and their struggles, and incredible natural gifts in the visual arts and creative writing, along with the passion to serve and improve the health of others, provide her an incredibly unique opportunity to make a significant impact. We could not be prouder as an institution of her work, her gifts, and the caring, compassionate future physician she is becoming. It is hard to predict where these talents will take her as she matures in her medical education, but we are all incredibly excited to support her endeavors and celebrate the impact she will have on improving lives in our global community.

Angela Peterman Mihalic, ${ }^{1,}$

'Associate Dean for Student Affairs. Professor of Pediatrics, University of Texas Southwestern Medical School. Angela.Mihalic@utsouthwestern.edu

Acknowledgments: None.

Conflict of Interest Statement at Funding: The Author has no funding, financial relationships or conflicts of interest to disclose.

Author Contributions: Write the manuscript, Approval of the final version: APM.

Cite as: Mihalic AP. Grains of Sand and an Artist's Hands. Int J Med Students. 2014 Nov-2015 Mar;3(1):72. 


\section{Response to Medical Students' Attitudes towards Female Sex Workers}

\section{To the Editor,}

The article by Nakagawa and Akpinar-Elci on medical students knowledge and attitudes toward female sex workers and their occupational risk factors left us with ambiguous reflections. The crux of this study raises an important issue: sex work, sexual abuse toward women, and sexually transmitted diseases (STDs) are big problems and should be widely discussed in the medical environment. It is essential to provide care to female sex workers through educating medical students and young doctors, regardless of their religious and upbringing influences. It is, however, important to understand cultural and regional differences in the perception of prostitution due to the ubiquitousness of this issue in different parts of world. We strongly agree with Nakagawa and Akpinar-Elci's statement on the importance of providing care to female sex workers as a vulnerable group.

However, the paper seems to be misleading due to several problems with the group size and selection, as well as with the presentation of the data. The distribution of 292 students across 56 countries does not reflect the distribution of medical students in the world. ${ }^{2}$ Students from five countries (United States, Italy, Iran, Brazil, and a country wrongly identified as Italy with a line extending to the island of Sicily) made up $52.1 \%$ of the study sample, while in forty-two of the countries studied, only three or less students ( $1 \%$ of the total study sample or less) participated in the online survey. This is not a representative sample of the world population of medical students, an issue which could undermine the validity of the study results. ${ }^{3-4}$ In addition, Figure 1 shown in the Nakagawa and Akpinar-Elci paper presents misleading data. Italy is marked twice (10.3\%, $\mathrm{n}=30$ and $5.8 \%, \mathrm{n}=17)$, and this information is not consistent with the given text. Three countries are mentioned in the article and only two of them are correctly represented in the figure. A complete table providing the country demographics (student distribution and their responses) published as an appendix would be a valuable addition to the manuscript.

In addition to errors in the first figure, the statistical analysis is not sufficiently described in the text. There are neither exact results of the mentioned two-sample t-tests nor measured attitudes. Furthermore, the stratification of the data seems to be insufficient; there is no detailed information about the educational background of sampled individuals. The students should be divided into additional groups, for example, according to the Gross Domestic Product (GDP) per capita or to their religion. Every religion has different attitudes towards prostitution, which was not considered in the results. ${ }^{5}$ Furthermore, the legality of prostitution in specific countries is not clearly identified. Many countries do not have regulated laws about the sex industry. ${ }^{6}$ All of this may lead to erroneous conclusions and misunderstanding.

In conclusion, the study by Nakagawa and Akpinar-Elci contributed a great deal to the understanding of the problems faced by female sex workers. There are, however, several components of the study design that are important to bring to the attention of readers to facilitate a more comprehensive discussion on this topic. We believe that this paper will definitely prove to be an eminent study of this subject.
Hanna Garnier,' Jakub Wisniewski. ${ }^{2}$

'BS; President of Pediatric Surgery and Urology students' scientific association, Medical University of Gdansk, Poland.

2BS; Founder and President of Pediatric Surgery and Urology students' scientific association in Medical University of Gdansk, Poland; vice-president of Students' Sonography Association Medical University of Gdansk, Poland. garnierhanna@gmail.com

\section{References}

1. Nakagawa JT, Akpinar-Elci M. Medical students' knowledge and attitudes toward female sex workers and their occupational risk factors. Int J Med Students. 2014 Jul-0ct;2(3):104-8.

2. Duvivier RJ, Boulet JR, Opalek A, van Zanten M, Norcini J. Overview of the world's medical schools: an update. Med Educ. 2014 Sep;48(9):860-9. 3. Häder S, Lynn P. How representative can a multi-nation survey be? In: Jowell R, Roberts C, Fitzgerald R, Eva G, editors. Measuring attitudes cross-nationally: lessons from the European Social Survey. London (England): Sage Publications Ltd; 2007.

4. Bartlett JE, Kotrlik JW, Higgins CC. Organizational research: determining appropriate sample size in survey research. Inf Technol Learn Perform J. 2001 Spring; 19(1):43-50.

5. Le Gall A, Mullet E, Rivière Shafighi $S$. Age, religious beliefs, and sexual attitudes. I Sex Res. 2002 Aug;39(3):207-16.

6. Munro VE, Giusta DM, editors. Demanding sex: critical reflections on the regulation of prostitution. Aldershot (England): Ashgate; 2008.

\section{Acknowledgments: None.}

Conflict of Interest Statement a Funding: The Author has no funding, financial relationships or conflicts of interest to disclose.

Author Contributions: Conception and design the work/idea, Analysis and interpretation of data, Write the manuscript: HG, JW. Critical revision of the manuscript: JW. Approval of the final version: HG.

Cite as: Garnier H, Wisniewski J. Response to Medical Students' Attitudes towards Female Sex Workers. Int J Med Students. 2014 Nov-2015 Mar;3(1):73.
About the Author: Hanna Carnier is currently a final year medical student in a dical University of Cdansk, Gdansk, Poland. She is the President of Pediatric Surgery and Urology Students Scientific Association at the Medical University of cdansk. six year program at the Me 